
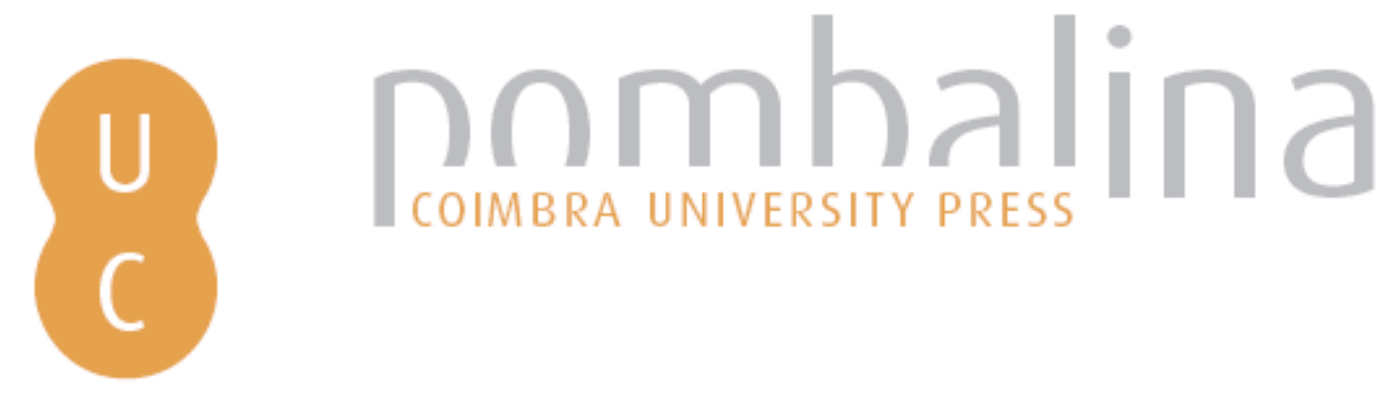

\title{
El escorpión blanco, una recreación de Medea
}
Autor(es):
Silventi, María Cristina
Publicado por: Imprensa da Universidade de Coimbra
URL persistente:
URI:http://hdl.handle.net/10316.2/43032
DOI:
DOI:https://doi.org/10.14195/9789892614397_31

Accessed : $\quad$ 26-Apr-2023 14:07:49

A navegação consulta e descarregamento dos títulos inseridos nas Bibliotecas Digitais UC Digitalis, UC Pombalina e UC Impactum, pressupõem a aceitação plena e sem reservas dos Termos e Condições de Uso destas Bibliotecas Digitais, disponíveis em https://digitalis.uc.pt/pt-pt/termos.

Conforme exposto nos referidos Termos e Condições de Uso, o descarregamento de títulos de acesso restrito requer uma licença válida de autorização devendo o utilizador aceder ao(s) documento(s) a partir de um endereço de IP da instituição detentora da supramencionada licença.

Ao utilizador é apenas permitido o descarregamento para uso pessoal, pelo que o emprego do(s) título(s) descarregado(s) para outro fim, designadamente comercial, carece de autorização do respetivo autor ou editor da obra.

Na medida em que todas as obras da UC Digitalis se encontram protegidas pelo Código do Direito de Autor e Direitos Conexos e demais legislação aplicável, toda a cópia, parcial ou total, deste documento, nos casos em que é legalmente admitida, deverá conter ou fazer-se acompanhar por este aviso. 


\section{Pervivencia del mundo clásico en la literatura:}

\section{tradición y relecturas}

\section{Aldo Rubén Pricco, Stella Maris Moro (coords.)}

IMPRENSA DA UNIVERSIDADE DE COIMBRA 


\title{
EL ESCORPIÓN BLANCO, UNA RECREACIÓN DE MEDEA (The White Scorpion, a recreation of Medea)
}

\author{
María Cristina Silventi (silventicris@gmail.com) \\ Universidad Nacional de Cuyo
}

Resumen - Las palabras dichas por la nodriza a comienzo de Medea de Eurípides nos sirven para centrar el monólogo de El escorpión blanco, una recreación de la misma tragedia del dramaturgo Daniel Fermani: "[...] mi señora, consume su vida en su habitación nupcial, sin que las palabras de ningún ser querido lleven alivio a su espíritu" (141-143) ${ }^{1}$. El personaje femenino es presentado en el instante exacto de la peripecia, que es diferente a la tradicional, puesto que no es ni brusca ni repentina, sino que se prolonga a través de todo el monólogo. Las circunstancias que la han conducido a ese estado de desolación se reflejan en sus palabras. Inclusive el filicidio aparece como un tema más de este lamento, a veces a modo de anticipación, otras ya ejecutado, para luego volver a retomarlo más que como hecho concreto, como parte de un lamento que vuelve una y otra vez cíclicamente. Medea no es la maga, la hechicera mitológica, es una mujer que sufre la decepción de una promesa y el agobio de la vejez. Su desilusión la lleva a plantearse cuestiones existenciales de carácter intemporal: la vida, la muerte, la maternidad, la vejez. Con un movimiento pendular sus reflexiones oscilan entre el pasado, donde la presencia de su hombre marcaba la plenitud de su existencia y el presente desbordado por el vacío provocado por la ausencia masculina.

Palabras clave: desengaño, maternidad, vida, muerte.

Abstract - The words spoken by the nurse at the beginning of Euripides' Medea serve us to focus on the monologue of The White Scorpion, a recreation of the same tragedy by the playwright Daniel Fermani: "[...] my wife, consumes her life in her bridal room, without no words from any nearest people bringing relief to her spirit" (141-143). The female character is presented at the exact moment of the incident, which is different from the traditional since it is neither abrupt nor sudden, but extends throughout the monologue. The circumstances that have led her to that state of desolation are reflected in her words. Even the filicide appears as an extra issue of this lament, some times as an anticipation, others already executed, to be taken up later as part of a lament that returns again and again cyclically rather than as a concrete fact. Medea is not the magician, the mythological sorceress, she is a woman who suffers the disappointment of a promise and the burden of old age. Her disappointment leads her to consider existential questions of a timeless character: life, death, motherhood, old age. With a back and forth movement her reflections swing between the past, where the presence

\footnotetext{
${ }^{1}$ Medina González, A. y López Férez, J. (trad.) (2000). Eurípides. Medea. Madrid: Gredos.
} 
of a man marked the fullness of her existence, and the present, overflowed by the emptiness caused by the male absence.

KeYwords: disappointment, maternity, life, death.

La pieza del dramaturgo mendocino, Daniel Fermani, es una propuesta original desde su misma estructura, pues es breve y consiste en un monólogo expuesto por la protagonista. Pero además, realiza otros aportes singulares en el planteo temático. Para poder referirnos a estas innovaciones con más claridad, vamos a partir del mito y luego recorrer los principales puntos de la tragedia de Eurípides, Medea, de modo de poder establecer una comparación entre las dos mujeres.

\section{El mito de Medea según Apolodoro}

Según la mitología, cuando Jasón llegó a la Cólquide a buscar el vellocino por encargo de Pelias, rey de Yolco, se encontró con Eetes, soberano del lugar. Este, antes de entregarle el vellocino, le impuso una prueba: uncir los toros, regalo de Hefesto que "estaban provistos de pezuñas de bronce y arrojaban fuego por la boca" (Libro 1, 23) ${ }^{2}$. A continuación, Apolodoro coloca en primer plano a Medea que había estado observando a Jasón y se había enamorado de él:

Mientras Jasón cavilaba cómo uncir los toros, Medea se enamoró de él; era una hechicera, hija de Eetes y de la oceánide Idía. Temiendo que los toros destrozaran a Jasón, prometió, sin conocimiento de su padre, ayudarle a uncirlos y conseguir el vellocino de oro si juraba tomarla por esposa y llevarla en su viaje a la Hélade. $(1,23)^{3}$

Por esta misma fuente sabemos que luego de obtener el vellocino, Jasón se hizo a la mar junto a Medea y su hermano Apsirto, a quien la propia hermana asesinó y lo fue arrojando por partes al mar para retrasar la persecución de su padre. Luego de cuatro meses de viaje, llegaron a Yolco y Jasón entregó el vellocino a Pelias. El héroe como quería vengarse del rey, pidió a Medea que por intermedio de sus poderes le diera muerte. "Esta se dirigió al palacio y persuadió a las hijas de Pelias a que despedazaran y cocieran a su padre, prometiéndoles

${ }^{2}$ Para las traducciones de Apolodoro, Calderón Felices 2002. Para la fuente, Frazer 1954.

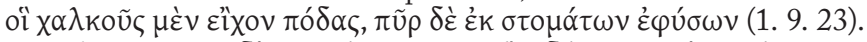

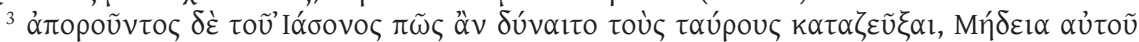

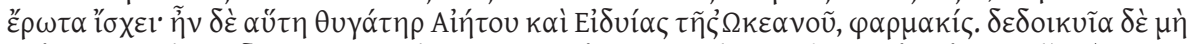

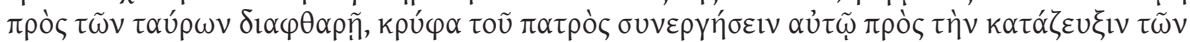

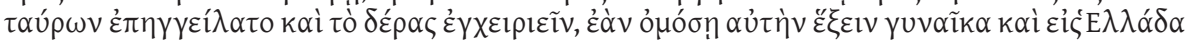

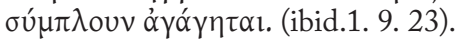


rejuvenecerlo con sus drogas [...] (1.27)4. Luego Acasto, el hijo de Pelias, expulsó de Yolco a la pareja. "Estos llegaron a Corinto y vivieron felices durante diez años, hasta que Creonte, rey de Corinto, prometió dar a su hija Glauce a Jasón quien abandonando a Medea se casó con ella" (1.28) .

\section{La tragedia de Eurípides}

En esta obra la nodriza cumple con la función específica del prólogo trágico y recuerda al público todo ese pasado que relaciona a Medea con Jasón hasta el momento en que este la abandona. Agrega, además, un tema indispensable para poder comprender la profundidad del agravio que Jasón ha infligido a Medea, esto es: Jasón ha faltado a los juramentos ${ }^{6}$ que le había dado respecto de su fidelidad: "Y Medea, la desdichada, objeto de ultraje, llama a gritos a los juramentos, invoca a la diestra dada, la mayor prueba de fidelidad, y pone a los dioses por testigos del pago que recibe de Jasón" 7 (20-24) ${ }^{8}$. En su parlamento la nodriza nos describe el estado anímico de la protagonista completamente destruida ${ }^{9}$ pues su buena fe ha sido traicionada. Medea consideraba que su matrimonio con Jasón a pesar de no poseer la anuencia de su padre, había sido un acuerdo basado en el amor y en la buena fe de la palabra empeñada y por eso había traicionado a los suyos, lo había seguido y le había dado hijos ${ }^{10}$. Esta falta de reciprocidad, por parte de Jasón, es el peor ultraje y por esto se desencadena la peripecia principal. A partir de este momento, Medea se debate entre el aniquilamiento moral, que

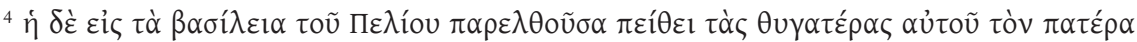

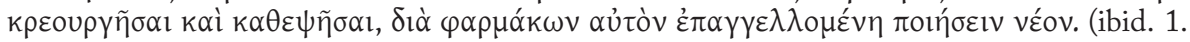
9. 27).

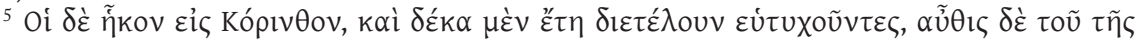

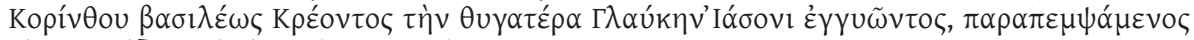

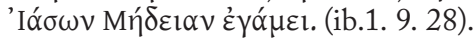

${ }^{6}$ El valor de la palabra empeñada era importantísimo entre los griegos que no necesitaban papeles para cumplirlas. Antígona hace referencia a estas leyes no escritas, pero de origen divino y por lo tanto, más válidas que las institucionales: "No pensaba que tus proclamas tuvieran tanto poder como para que un mortal pudiera transgredir las leyes no escritas e inquebrantables de los dioses" (S. Ant. 454-455). Alamillo 1992.

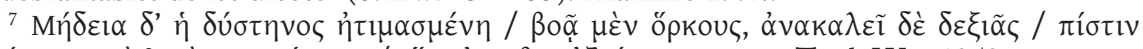

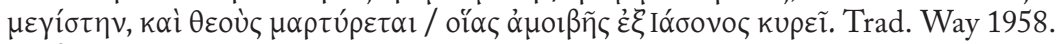

${ }^{8}$ Sigo la traducción de Medina González, López Férez 2000.

${ }_{9}$ Afirma López Férez 1988: 385: “[...], desde sus primeras obras Eurípides se preocupa por la actitud anímica de los personajes, expresando hábilmente el intrincado mundo de los sentimientos y las pasiones y mostrándose experto consumado en expresar las emociones íntimas, desde la cólera implacable de Medea, los desvanecimientos amorosos de Fedra, y la locura de Orestes, hasta la actitud, ya pacífica, ya desbordante y salvaje de las bacantes".

${ }^{10}$ Al respecto afirma Gambón 2009: 54: "Claramente se trata de una unión no convencional, fundada en la reciprocidad y sellada por los juramentos y las diestras estrechadas, un vínculo contractual que contrasta sensiblemente con la nueva unión real escogida por Jasón que sigue las pautas de un acuerdo homosocial entre kyrios". 
se traduce en un estado físico de abatimiento y la indignación vengativa que crece en el odio hasta las últimas consecuencias.

También a través de la nodriza conocemos el carácter de su ama y parte de lo que comenta sirve de anticipación de lo que va a suceder en la obra:

Ella odia a sus hijos y no se alegra al verlos, y temo que vaya a tramar algo inesperado, [pues su alma es violenta y no soportará el ultraje. Yo la conozco bien y me horroriza pensar que vaya a clavarse un afilado puñal a través del hígado, entrando en silencio en la habitación donde está extendido su lecho, o que vaya a matar al rey y a su esposa y después se le venga encima una desgracia mayor], pues ella es de temer. $(36-45)^{11}$

En el diálogo posterior entre el pedagogo y la nodriza se agrega un dato más que aumentará la situación desgraciada de Medea: "Pedagogo - He oído a alguien, [...] que Creonte, soberano de esta tierra, iba a expulsar de este suelo a estos niños con su madre" $(67-74)^{12}$.

La nodriza, como único recurso a su alcance, trata de mantener alejados a los niños de su madre, tal es la desconfianza que siente respecto de su señora:

Entrad, todo irá bien, dentro de la casa, hijos. Y tú, tenlos lo más apartados que puedas y no los acerques a su irritada madre, pues ya la he visto mirarlos con ojos fieros de toro, como tramando algo. No cesará en su cólera, lo sé bien, antes de desencadenarla sobre alguien $(89-94)^{13}$.

Es interesante destacar la relevancia que tienen en las tragedias de Eurípides los personajes que pertenecen a una capa social inferior. Frecuentemente aportan comentarios de carácter sentencioso que agregan conceptos muy relacionados con la época. Así, por ejemplo, el pedagogo afirma: "Las antiguas alianzas ceden el paso a las nuevas y aquel ya no es amigo de esta casa" (76-77) ${ }^{14}$. Versos lapidarios que están presentando una situación muy común en la época, pues Creusa (hija de Creonte) lleva ventaja sobre Medea, aun cuando esta última haya conformado una familia. Acorde con la ley contemporánea de Pericles, Medea

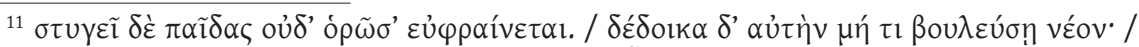

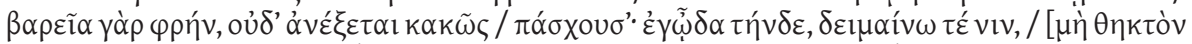

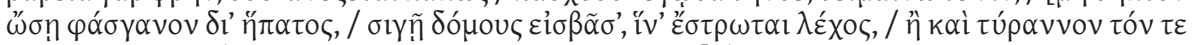

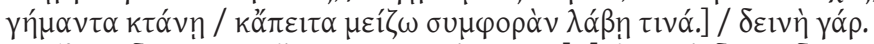

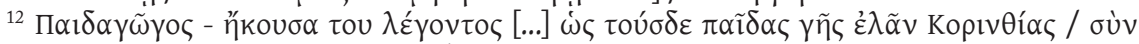

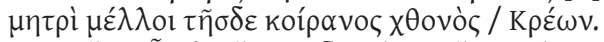

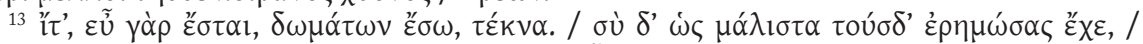

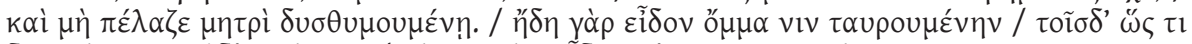

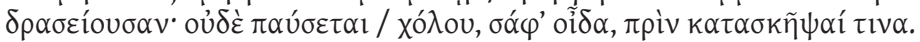

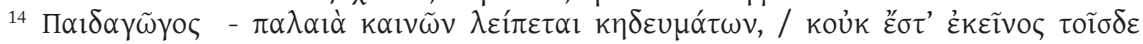

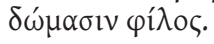


era una extranjera y por tanto el matrimonio no tenía valide $z^{15}$. Todo lo contrario ocurre con Creusa cuyo futuro matrimonio sería consolidado con una unión que respetará "las pautas de un acuerdo homosocial entre kyrioi" (Gambón 2009: 54).

Medea, sin dudas, está en condiciones de inferioridad absoluta, abandonada, de origen extranjero lo que implica exclusión social y en un futuro cercano, exiliada.

El porqué del exilio lo conocemos unos versos más adelante, cuando se presenta ante ella el mismo Creonte y le manifiesta el temor de que tome represalias, pues conoce su naturaleza heredada: "[...] eres de naturaleza hábil y experta en muchas artes maléficas [...]" $(85)^{16}$.

En efecto, según la mitología, Medea era nieta de Helio y de la maga Circe. Otras tradiciones míticas, como por ejemplo la que sigue Diodoro, Medea es hija de Hécate, patrona de las magas ${ }^{17}$. Ella misma se reconoce como nieta del sol y se dice a sí misma: "[...] tú, hija de un noble padre y progenie del Sol" (406) ${ }^{18}$. Lo cierto es que es conocida por su carácter de hechicera y en la tragedia esto se manifiesta en los obsequios que le envía a Creusa: un peplo y una corona de oro envenenados, que causarán su muerte y la de su padre. Los regalos son portados por sus propios hijos y con esta acción se cierra un círculo inevitable. Medea ha sido abandonada, no puede regresar a su oikos pues ha destruido todo lazo con este, en Corinto nunca dejará de ser extranjera y con fama justificada de hechicera, exiliada no tiene adónde ir y los corintios buscarán vengar la muerte del rey y Creusa en sus hijos. Todo esto sumado al temor de ser el motivo de la risa de los ciudadanos, la empuja a la decisión extrema de ultimar a sus hijos, pues de este modo se vengará en lo que más duele al hombre griego, su progenie. Al respecto comenta Hall (1997: 106): "The destruction of the kinship line is a major theme in tragedy. [...] it is a reason why Medea Chooses for Jason not his own death but the death of his new wife (On whom he could beget new heirs) and the deaths of his sons $[. .$.$] ".$

\section{EL ESCORPIÓN BLANCO}

En la recreación que el dramaturgo Daniel Fermani hace de esta tragedia, encontramos elementos que se vinculan estrechamente con la obra griega y el mito, pero también reconocemos aportes originales que dan al personaje una perspectiva renovada.

${ }^{15}$ Al respecto afirma Hall 1997: 104: "The polis consisted of a multiplicity of households, and it was in the household that the citizen body reproduced itself; the Athenian's claim to the privileges of citizenship depended upon his ability to prove that he emanated from a legitimate union of two Athenians, at least after 451 BC".

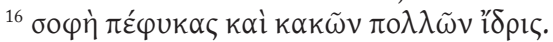

${ }^{17}$ Ver Grimal 2008: 336.

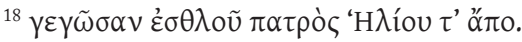


En el epígrafe conocemos el fundamento de la selección del título: "En este raro tipo de escorpión blanco, la hembra destruye la cría cuando el macho abandona el nido". Es decir, que el autor desde un comienzo está aludiendo a una reacción instintiva más que humana en Medea y veremos que de las características principales que hemos visto con antelación en las fuentes, solo busca resaltar la pasión desenfrenada de la protagonista y el poder destructivo del incumplimiento de la promesa dada.

El mismo abatimiento que, como hemos visto, describe la nodriza en la tragedia de Eurípides, lo percibimos aquí a través de las palabras cargadas de amargura y escepticismo de la mujer. Su monólogo, por momentos se asemeja a un "libre fluir de la conciencia" que deja entrever el desencanto y abandono de su persona. El nuevo matrimonio de Jasón ya está consumado y la obra sólo presenta las consecuencias de esta traición. El tempo interior del monólogo es lento, casi detenido y su punto de partida es la peripecia trágica que no es brusca, sino que opera como desencadenante de todo el monólogo. Con movimiento pendular la protagonista oscila entre un pensamiento que se extiende más allá de su problemática personal y el replanteo de su propia existencia.

Comienza el monólogo haciendo referencia al ciclo de la vida en su eterno devenir a través del recurso clásico del ubi sunt:

Vida y muerte en perfecta armonía. Perecía la semilla para dejar paso al tallo vigoroso. ¿De dónde surgía? ¿De dónde esa rama verde erguida y esas hojas De dónde habían nacido De qué fuerza $Y$ esos pimpollos y luego esos pétalos de un color que nunca antes De dónde De dónde si no de la amorosa batalla entre vida y muerte Del abrazo silencioso que libera y arranca y abre el camino a la luz ${ }^{19}$.

La elisión de signos gráficos así como los espacios en blanco hacen visible el carácter ambiguo de las interrogaciones retóricas. A veces, el discurso se prolonga, como si la protagonista quedara por momentos en un estado de vacío mental, de enajenación.

La devoción de Medea hacia Jasón y la traición de este adquieren una dimensión cósmica y lo que debiera ser necesario y natural para la vida, se detiene y transforma en dolor enfermizo en la protagonista, que todo lo observa desde esta perspectiva de profundo rencor.

La vida ha perdido el sentido, pues Jasón ha atentado contra lo más sagrado que implica una promesa y ha quebrado la seguridad y la reciprocidad que supone el juramento. La destrucción de esta lealtad, la mentira es lo que enferma a Medea, pues la considera como un acto impropio y opuesto a la naturaleza y

\footnotetext{
${ }^{19}$ Fermani 2012: 1.
} 
al hombre: "Mentir no pueden los elementos. Mentir no pueden las voces que libera la montaña, el canto mudo de las piedras de mi calle. Mentidas no fueron las palabras que un día sentí rozar y atravesar mi cuerpo joven”"

La decepción alimenta una pasión diferente que la paraliza, pues el abandono de su hombre implica dejarla en un estado marginal de la vida, por eso el fluir vital también se detiene. El lugar que ella ocupaba como seguro, el oikos al que antes hemos hecho referencia, ha desaparecido. Junto con la mentira, Medea pierde su espacio social y lo que ella consideraba como un estado permanente se ha derrumbado:

¿Es posible?

Siempre. Gritaban la tierra. Siempre, murmuraba el agua en los océanos tempestuosos.

Siempre, dijo el aire y diseñó las nubes y su lluvia fecunda ${ }^{21}$.

Para Medea la promesa era tan cierta como la existencia misma de la tierra y sus océanos, era el fundamento de su amor. Pero la mentira fue más fuerte y su poder, devastador. Todo se modifica a partir de esto:

Pero otra verdad se impuso sobre la Tierra. Y esa verdad ha barrido todo lo demás. Piedras hojas viento océanos aire nubes Aquello que conocí y callé. Nada de todo aquello que era es ya. Nada que sea testigo de la mano protectora de la vida y su dulce caricia sobre la cara devastada de Este Día Funesto ${ }^{22}$.

La falta de puntuación hace de la enumeración un "libre fluir" como si por un instante Medea tomara conciencia de su situación y esto se ve acentuado por la interrogación retórica que dirige a sus hijos a continuación, como si recién los descubriera: "Hijos míos, ¿por qué lloran?”23. A su vez, la interrogación delimita un segundo momento que se extiende hasta el final y que se relaciona con la idea de la muerte y la venganza: «Mensajero de la muerte soy, que no de la vida. $\mathrm{Ha}$ terminado el tiempo que el ritmo de las cosas señalaba para sellar entre vida y muerte una alianza. Ha quedado la muerte, y es a ella que yo estoy anunciando ${ }^{24}$.

El cuestionamiento de Medea nos recuerda la tragedia de Eurípides (799780): “Qué ganancia tengo con vivir? No poseo ni patria, ni casa, ni refugio de mis males”. En el monólogo Medea ve como concluida su vida. No espera nada. "Seré nadie. Y mis hijos. Nadie serán. Como nadie es todo aquello que de la muerte se vuelve posesión”25.

\footnotetext{
${ }^{20}$ Fermani 2012: 1.

${ }^{21}$ Fermani 2012: 1.

${ }^{22}$ Fermani 2012: 1.

${ }^{23}$ Fermani 2012: 1.

${ }^{24}$ Fermani 2012: 1 .

${ }^{25}$ Fermani 2012: 2.
} 
En un espacio indeterminado, es la mujer cansada que entre lamentos analiza su propia existencia, la decisión de ser madre para justificar su presencia y la devoción por su hombre. Una devoción que se altera en enfermedad y muerte. Porque ahora es la mujer despreciada por su vejez y desplazada por otra más joven. Un estado que ella misma describe con cruel realismo en la presencia silenciosa de la nodriza y que se constituye en su propio espejo: "rostro surcado", "paso arrastrado", "manos deformes", "cuerpo retorcido", "Sombra no luz y mal olor", "olor a olvido" 26 .

Con diferentes recursos el autor ha sabido expresar el debate interior de la protagonista. Así, por ejemplo, mediante un oxymoron manifiesta el amor por sus hijos y el odio a Jasón "Hijos amados Odiados pedazos de su adorada carne" 27 . Por momentos, toda la fuerza de su odio vengativo se deshace cuando surge en Medea su amor maternal y se refiere a sus hijos como seres frágiles. El uso del diminutivo "cuerpitos blancos delicados" o de la comparación, cuando hace referencia a los párpados de sus niños como "alas diminutas de las luciérnagas en las noches de verano" ilustran este sentimiento. Es la madre que en la indefensión de sus hijos manifiesta su profunda ternura. Sin embargo, ese momento de debilidad es solo un breve instante y lo cierra con una frase sentenciosa: "Pasión les dio la vida Pasión se las quitó"28.

\section{LA ORIGINALIDAD DEL AUTOR}

Contrariamente a la tradición mítica en donde uno de los elementos principales de la figura de Medea era su cualidad de hechicera, en la obra es presentada como una mujer común, cuyo odio la hace desear tener poderes especiales para vengarse: "Bruja quisiera ser Bruja y maga para quemar viva aquella joven inconsciente que me lo roba [...]"29.

Por otra parte, Medea es presentada como una mujer vieja, cualidad que la coloca en absoluta desventaja frente a la "avasalladora furia de la juventud" de su rival.

En su monólogo se manifiesta el odio hacia su hombre, pero también hacia sí misma. Es este doble odio el que justifica la muerte de sus hijos. Ella los mata para evitarles el sufrimiento que implica vivir: “'Saben lo que es crecer? ¿Querían conocer la madurez? Si la muerte les doy como una vez la luz les di es también para ahorrarles este dolor ${ }^{{ }^{30}}$.

Pero también para impedir que en el futuro se parezcan a su padre, cuya

\footnotetext{
${ }^{26}$ Fermani 2012: 3.

${ }^{27}$ Fermani 2012: 3 .

${ }^{28}$ Fermani 2012: 3.

${ }^{29} \mathrm{Ib} .4$.

${ }^{30}$ Ib.3.
} 
conducta no es de hombres y por eso la imagen de Jasón se ha desdibujado para Medea y ahora lo ve como un ridículo "fantoche".

El ensimismamiento se acentúa en el fluir desordenado del discurso. Preguntas, respuestas, inclusive son confusos los tiempos referidos a la muerte de sus hijos. Por momentos, la madre les habla como si ya estuvieran muertos "Ah, ¿en qué infierno vagan [...]" y luego los llama, en el mismo fragmento, "aférrense a mi falda y lloren" ${ }^{31}$.

La intervención de la nodriza es solo una excusa para acentuar aún más la terrible visión que tiene sobre la vejez. Su llanto es parte de la flaqueza y debilidad de los viejos "Llorás, vieja tonta" "Secá esas lágrimas estúpidas" ${ }^{2}$. La nodriza es la presencia muda de la vejez, que atiende a otra vieja, Medea. Con movimiento mecánico le cepilla sus cabellos en un intento por quitar las hebras blancas que evidencian el paso del tiempo.

La comunión que existe entre ambas mujeres le permite a Medea abandonarse en el regazo de su nodriza, compañera de toda una vida, pero su debilidad dura instantes.

El tempo se agiliza, Medea habla a sus hijos ya muertos. Luego ordena a la nodriza que los cubra y casi al mismo tiempo, observa que es de día.

A un solo párrafo reduce la justificación de su acto: "Llorar lo quiero ver. Llorar por mí por mi juventud perdida por mi carne marchita no lo he visto. Entonces llorar por estas muertes irremediables lo quiero sentir. [...] Bálsamo será para mi pecho de madre asesina su pena”33.

Finalmente la mujer bárbara euripídea que huye sobre un carro tirado por dragones alados con los cadáveres de sus hijos y que en breve diálogo con Jasón le anuncia su pronta muerte, es reducida en esta pieza a una simple mujer que ordena a su nodriza anunciar su propia locura.

Con el día, Medea enfrenta los hechos. Su vigilia ha durado lo que el monólogo. Sin embargo, nos da la impresión de que ha pasado largo tiempo en un estado de postración acompañada de los cadáveres de sus hijos y de la nodriza y si bien toma, por momentos, conciencia de esas presencias, vuelve una y otra vez a su lamento. Un lamento que parece un murmullo de rezo, donde se cuestiona el sentido de su propia existencia al punto de llegar a despreciarla.

Sus últimas palabras sólo expresan órdenes, ni siquiera manifiestan emoción. Es la mujer destruida que ya no tiene nada que perder. Nos deja la impresión de que ni siquiera le importa qué ocurrirá con Jasón, así como tampoco qué pasará con ella.

\footnotetext{
${ }^{31} \mathrm{Ib} .3$.

${ }^{32}$ Fermani 2012: 4.

${ }^{33}$ Fermani 2012: 5.
} 


\section{Bibliografía}

\section{Fuentes}

Fermani, D. (2012), El escorpión blanco. Sin publicar.

Frazer, J. (1954), Apollodorus. The Library. The Loeb Classical Library. Cambridge, Massachusetts: Harvard University Press: London: William Heinemann, v. I.

Way, A., Page, T. et alii (1958), Euripides. IV. The Loeb Classical Library, Cambridge, Massachusetts: Harvard University Press, London: William Heinemann.

\section{Traducciones}

Alamillo, A. (1992), Sófocles. Tragedias. Madrid: Gredos.

Calderón Felices, J. (2002), Apolodoro. Biblioteca. Madrid: Akal.

Medina González, A., López Férez, J. (2000), Eurípides. Tragedias. I. Madrid: Gredos.

\section{Bibliografía específica}

Hall, E. (1997), "The Sociology of Athenian tragedy", in Easterling, P., The Cambridge Companion to Greek Tragedy. Cambridge: University Press.

Gambón, L. (2009), La institución imaginaria del oikos en la tragedia de Eurípides. Bahía Blanca: Universidad Nacional del Sur- Ediuns.

Grimal, P. (2008), Diccionario de Mitología. Buenos Aires: Paidós.

López Férez, J. A. (1988), Historia de la Literatura Griega. Madrid: Cátedra. 